\title{
A Randomized Trial. Comparing Herniorrafia Modifield Desarda Repair and Hernioplastia Lichtenstein Repair for Inguinal Hernia (Study of 1242 Patients)
}

Dr. Pedro Rolando Lòpez Rodrìguez ${ }^{1}$ Dr. Eduardo Garcia Castilloº ${ }^{2}$ Dr Olga Caridad Leòn Gonzàlez Dr. Luis Manuel Danta Fundora ${ }^{4}$, Dr. Pastor Villavicencio Crespo ${ }^{5}$, Dr. Lais Angèlica Ceruto Ortiz ${ }^{6}$

${ }^{1}$ Specialist of I Degree and II Degree in general surgery, Axiliary Professor, Consulting Professor and Auxiliary Researcher, Enrique Cabrera General Teaching Hospital, La Habana, Cuba.

${ }^{2}$ Specialist of I Degree in general surgery, Assistant Professor, Enrique Cabrera General Teaching Hospital La Habana, Cuba.

${ }^{3}$ Specialist of I Degree in general surgery, Auxiliary Professor and Auxiliary Researcher

Enrique Cabrera General Teaching Hospital, La Habana, Cuba.

${ }^{4,5}$ Specialist of I Degree in general surgery and Assistant Professor, Enrique Cabrera General Teaching Hospital La Habana, Cuba.

${ }^{6}$ Second year resident in general surgery, Enrique Cabrera General Teaching Hospital, La Habana, Cuba. lopezp@infomed.sld.cu/pedro.rolando.lopez42@gmail.com

*Corresponding Author: Pedro Rolando López Rodríguez, National Hospital, Continental Street No. 152 between D'Strampes Street and Goicuría Street, Sevillano, 10 de Octubre, Havana, Cuba.

Abstract

Introduction: The objective of this study is to compare the outcomes of Modified Desarda repair no mesh and Lichtenstein repair for inguinal hernia.

Patients and Methods: This is a prospective randomized controlled trial study of 1242 patients having 1313 hernias operated from January 2008 to December 2018. 640 patients were operated using Lichtenstein repair and 602 using Desarda repair. The variables like age, sex, location, type of hernia, tolerance to local anesthesia, duration of surgery, pain on the first, third and fifth day, hospital stay, complications, re-explorations, morbidity and time to return to normal activities were analyzed. Follow up period was from 1-10 years (median 6.5 years).

Results: There were no significant differences regarding age, sex, location, type of hernia, and pain in both the groups. The operation time was 52 minutes in Modified Desarda group and 42 minutes in the Lichtenstein group that is significant $(p<0.05)$. The recurrence was $0.0 \%$ in Modified Desarda group and $0.3 \%$ in Lichtenstein group. But, there were 8 cases of infection to the polypropylene mesh in the Lichtenstein group, 2 of this required reexploration. The morbidity was also significantly more in Lichtenstein group $(7,0 \%)$ as compared to Modified Desarda group (3.6\%). The mean time to return to work in the Modified Desarda group was 8.26 days while a mean of 12.58 days was in the Lichtenstein group. The mean hospital stay was 29 hrs. in Modified Desarda group while it was 49 hours in the Lichtenstein group in those patients who were hospitalized.

Conclusions: Modified Desarda repair scores significantly over the Lichtenstein repair in all respects including re-explorations and morbidity. Modified Desarda repair is a better choice as compared with Lichtenstein repair.

Keywords: Desarda Repair; Inguinal Hernia; Lichtenstein Repair; Randomized Trial 
A Randomized Trial. Comparing Herniorrafia Modifield Desarda Repair and Hernioplastia Lichtenstein Repair for Inguinal Hernia (Study of 1242 Patients)

\section{INTRODUCTION}

In 1890, Eduardo Bassini described suture repair for inguinal hernia. This was a massive leap forward and has been the basis of open repair for over 100 years. The surgeon enters the inguinal canal by opening its anterior wall, the external oblique aponeurosis. The spermatic cord is dissected free and the presence of a lateral or a medial hernia is confirmed. The sac of a lateral hernia is separated from the cord, opened and any contents reduced. The sac is then sutured closed at its neck and excess sac removed. If there is a medial hernia, then it is inverted and the transversalis fascia is suture plicated. Sutures, are now placed between the conjoint tendon above and the inguinal ligament below, extending from the pubic tubercle to the deep inguinal ring. The posterior wall of the inguinal canal is thus strengthened.10ver 150 modifications to the Bassini operation have been described with little or no benefit except for the Should ice modification. In this operation, the transversalis fascia is opened by a central incision from deep inguinal ring to the pubic tubercle and then closed to create a double-thick, two-layered posterior wall (double breasting). The external oblique is closed in similar fashion. Expert centres have reported lifetime failure rates of less than 2 per cent after Should ice repair but it is a technically demanding operation which, in general hands, gives results identical to the Bassini repair.1,24.

The surgeons use different techniques in Cuba for inguinal hernia repair like Bassini or Should ice and its modifications or different types of mesh repairs. The standard mesh is not available at many places and it is expensive also. Hernia treatment has become a health problem because of its social, economic and labour implications due to its high incidence in our population [1]. Until recently, the only parameters to be evaluated were recurrence, complication rates etc. Today, other parameters like cost, post-surgery wellbeing and quality of life have gained importance. The demand of general surgeons is to identify operations that are simple to perform without the need for complicated dissection and with low complication and recurrence rates. Avoidance of use of foreign material where possible is a basic surgical principal. The authors read about the Desarda repair which seems be simple in concept, avoids the use of mesh and gives the desired results. This repair is based on the concept of providing a strong and physiologically dynamic posterior wall to the inguinal canal. An undetached strip of the aponeurosis of the external oblique muscle replaces the absent aponeurotic element in the posterior wall and the weakened conjoint muscle receives additional strength from the external oblique muscle to keep it physiologically dynamic [2]. There are still many controversies to answer. Which is the best technique for repair? [3] Is hernioplasty better than herniorrhaphy? Which is the best technique for hernioplasty or herniorrhaphy? Does laparoscopic surgery have a better cost-efficiency than open surgery? Is mesh necessary in all inguinal hernia repairs? The objective of this study is to re-evaluate the Lichtenstein mesh repair and compare it with the novel and "No mesh, physiological repair" described by Modified Desarda Technique.

\section{METHOD}

This study was designed as a RCT (Randomized Controlled Clinical Trial) among the 1313 patients (602 patients of Modified Desarda's technique \{modification of Desarda's technique by adding Modified Bassini's technique [Darn with continuoussuturing with nonabsorbable polypropylenesuture]\} and 640 patients of Lichtenstein procedure alone) of inguinal herniain Surgery Unit 1 \& 2, Enrique Cabrera Hospital, Havana Cuba from a period of January 2008 to December 2018 with a viewto depict the short \& intermediate term (05 years) outcomes of newly proposed Modified Desarda's technique in contrast to Lichtenstein procedure 24. All the patients from both sexes older than 16 years with primary and recurrent inguinal hernias were included. Patients operated on emergency basis were excluded. The diagnosis of inguinal hernia and its type was made by clinical examination. Information was given to the patients as regards the anesthetic procedures. The patient chose type of anaesthesia after discussion with the surgeon. The Randomization was performed using a consecutively numbered, sealed envelope, which was opened, in theatre and all patients having an even number were operated by the Lichtenstein and uneven numbers by the modified Desarda technique. The operating surgeon completed a data sheet. The operating surgeon was at consultant level for all operations.

The evaluator was also a surgeon of consultant level. All patients signed a written informed consent. Approval of the local ethical committee was given prior to the onset of the study. Modified Desarda repair was performed according to the surgical technique described by Dr. Desarda and mesh prosthesis repair was undertaken as described in the 
A Randomized Trial. Comparing Herniorrafia Modifield Desarda Repair and Hernioplastia Lichtenstein Repair for Inguinal Hernia (Study of 1242 Patients)

textbooks. Prophylactic antibiotic was administered in the operating room before surgery (Cefazoline 1g.) in the Lichtenstein group only. All patients were discharged as soon as their post-surgical recovery allowed, and all patients were instructed to do daily, routine, non-strenuous work after discharge. A nonsteroidal anti-inflammatory (Diclofanac) analgesic was prescribed for a period of 5 days and continued if required. The consultants followed all the patients at 8 days, 1 month, 6 months and then yearrequired. The consultants followed all the patients at 8 days, 1 month, 6 months and then yearly thereafter. A data sheet was completed by the operating surgeon

including type of hernia (Nyhus classification) [4], anaesthesia, technical details and intra-operative complications. At discharge, further data was added including any early post-operative complications. Patients were asked to complete a pain score on the first, third and fifth day after surgery using a linear analogue scale $[5,6]$. At first follow up, one month after surgery, further data were collected including time to return to normal activities. The Student T test was used to compare the independent measures and the Mann Whitney-U test for non-parametric data. The Chi-squared test and Fisher's exact test were used to measure the association between quality variables.

\section{RESULTS}

There was no significant difference in relation to sex, age, location and type of inguinal hernia in both the groups. (Table 1).

Table 1. Age, Sex, Location and Type of Hernia

\begin{tabular}{|c|c|c|c|c|}
\hline \multirow[t]{2}{*}{ AGE, SEX, LOCATION } & \multicolumn{4}{|c|}{ SURGICAL TECHNIQUE } \\
\hline & \multicolumn{2}{|c|}{ LICHTENSTEIN GROUP $\mathrm{n}=640$} & \multicolumn{2}{|c|}{ MODIFIELD DESRDA $n=602$} \\
\hline \multirow[t]{2}{*}{ MEDIAN AGE } & \multicolumn{2}{|c|}{57,3} & \multicolumn{2}{|c|}{58,1} \\
\hline & No. & $\%$ & No. & $\%$ \\
\hline \multicolumn{5}{|l|}{ SEX } \\
\hline MALE & 585 & 91,4 & 558 & 92,7 \\
\hline FEMALE & 55 & 8,6 & 44 & 7,3 \\
\hline \multicolumn{5}{|l|}{ LOCATION } \\
\hline RIGHT & 305 & 47,6 & 295 & 49,0 \\
\hline LEFT & 291 & 45,4 & 280 & 46,5 \\
\hline BILATERAL & 44 & & 27 & 4,5 \\
\hline \multicolumn{5}{|l|}{ TYPE OF HERNIA } \\
\hline IY II & 277 & 43,2 & 296 & 49,2 \\
\hline IIIa IIIb & 313 & 49,0 & 279 & 46,3 \\
\hline IV & 50 & 7,8 & 27 & 4,5 \\
\hline
\end{tabular}

Local anesthesia was used in 279 patients in Lichtenstein group and 379 patients in the Desarda group. All those 658 (53.0\%) patients were operated on as outpatient basis without hospitalization. In

Table 2. Anesthesia and Hospital Stay

\begin{tabular}{|l|l|l|l|l|}
\hline ANESTHESIA AND HOSPITALSTAY & \multicolumn{1}{l|}{ SURGICAL TECHNIQUE } \\
\hline & LICHTENSTEIN GROUP n=640 & \multicolumn{2}{l|}{ MODIFIELD DESARDA n=602 } \\
\hline & No. & $\%$ & No. & $\%$ \\
\hline ANESTHESIA & 279 & 43,6 & 379 & 63,0 \\
\hline LOCAL & 315 & 49,2 & 203 & 33,7 \\
\hline SPINAL & 46 & 7,2 & 20 & 3,0 \\
\hline GENERAL & 273 & 42,6 & 377 & 62,6 \\
\hline HOSPITALIZATION & 310 & 48,4 & 211 & 35,0 \\
\hline Outdoor surgery without Hospitalization & 57 & 9,0 & 14 & 2,4 \\
\hline Short Term Hospitalization (<3days) & & & \\
\hline Long Term Hospitalization(>3days) & 57 &
\end{tabular}

Open Access Journal of Internal Medicine V2 . I2 . 2019

the remainder of 584 patients who were treated as in-patients,the mean hospital stay was 27 hours in Desarda group and 47 hours in the Lichtenstein group $(\mathrm{p}<0.05)$ (Table 2). 
A Randomized Trial. Comparing Herniorrafia Modifield Desarda Repair and Hernioplastia Lichtenstein Repair for Inguinal Hernia (Study of 1242 Patients)

Tolerance to local anesthesia was good during surgery in $68 \%$ and $67 \%$ respectively (NS). The mean duration of surgery was 42 minutes for Lichtenstein and 52 minutes for Desarda group $(\mathrm{p}<0.05)$. Analysis of pain scores from day one to day 5 showed no significant difference (Table 3).

Table 3. Duration of Surgery and Pain

\begin{tabular}{|c|c|c|c|c|}
\hline DURATION TOLERANCE AND PAIN & \multicolumn{4}{|c|}{ SURGICAL TECHNIQUE } \\
\hline & \multicolumn{2}{|c|}{ LICHTENSTEIN GROUP } & \multicolumn{2}{|c|}{ MODIFIELD DESARDA GROUP } \\
\hline & \multicolumn{2}{|c|}{$\mathrm{N}=640$} & \multicolumn{2}{|c|}{$\mathrm{N}=602$} \\
\hline \multicolumn{5}{|l|}{ DURATION OF SURGERY } \\
\hline \multirow[t]{2}{*}{ AVERAGE } & \multicolumn{2}{|c|}{$42 \mathrm{mts}}$. & \multicolumn{2}{|c|}{$52 \mathrm{mts}}$. \\
\hline & No. & $\%$ & No. & $\%$ \\
\hline \multicolumn{5}{|l|}{ PAIN : MILD TO MODERATE } \\
\hline First Day & 333 & 52,0 & 348 & 57,8 \\
\hline UP To Third Day & 230 & 36,0 & 194 & 32,2 \\
\hline Upto Fifth Day & 77 & 12,0 & 60 & 10,0 \\
\hline
\end{tabular}

There was no incidence of severe pain or chronic groin pain in both the groups

There was no incidence of severe pain in either group. The recurrence rate was $0.0 \%$ in the Desarda group, and $0.3 \%$ in the Lichtenstein group (NS). Four patients in the Lichtenstein group required re-exploration and mesh removal for the chronic suppuration. These patients had chronic suppuration, motivated by the rejection of the mesh which caused the mesh to be removed. Thus $0.5 \%$ of patients in the Lichtenstein group required a further surgical intervention for either recurrence or sepsis which was significantly higher than the Desarda group $(\mathrm{p}<0.05)$. All the patients were operated by the same surgeon and his helpers. (Table 4).

Table 4. Recurrence and Re-Exploration.

\begin{tabular}{|l|l|l|l|l|}
\hline LICHTENSTEIN GROUP $\mathrm{n}=640$ & 4 Mesh Removal for sepsis & 0,50 & 2 Recurrence & $0,30 \%$ \\
\hline MODIFIELD DESARDA GROUP $\mathrm{n}=602$ & - & - & 0 Recurrence & $0,00 \%$ \\
\hline
\end{tabular}

The seroma was the complication that most complications in the Lichtenstein group and 22 (3.6\%) frequently occurred with 18 patients in both groups patients showed complications in the Desarda group (1.4\%).45 (7.0\%) patients developed post-operative $\quad(\mathrm{p}<0.05)$ (Table 5).

Table 5. Morbidity

\begin{tabular}{|c|c|c|c|c|c|c|}
\hline \multirow[t]{3}{*}{ MORBIDITY } & \multicolumn{6}{|c|}{ SURGICAL TECHNIQUE } \\
\hline & \multicolumn{2}{|c|}{ Lichtenstein Group $n=640$} & \multicolumn{2}{|c|}{ Modifield Desarda Group n= 602} & \multicolumn{2}{|c|}{ Total $n=1242$} \\
\hline & No. & $\%$ & No. & $\%$ & No. & $\%$ \\
\hline Seroma & 12 & 1,8 & 6 & 1,0 & 18 & 1,4 \\
\hline Mild Infection & 8 & 1,2 & 6 & 1,0 & 14 & 1,1 \\
\hline Hematoma & 7 & 1,0 & 4 & 0,6 & 11 & $0 ` 8$ \\
\hline Orchitis & 5 & 0,7 & 2 & 0,3 & 7 & 0,5 \\
\hline Testicular atrophy & 2 & 0,3 & - & - & 2 & 0,1 \\
\hline Sepsis without re-exploration & 4 & 0,6 & - & - & 4 & 0,3 \\
\hline Sepsis with re-exploration & 2 & 0,3 & - & - & 2 & 0,1 \\
\hline Bradycardia & 4 & 0,6 & 4 & 0,6 & 8 & 0,6 \\
\hline Recurrence & 2 & 0,3 & 0 & 0 & 2 & 0,1 \\
\hline TotaL & 45 & 7,0 & 22 & 3,6 & 67 & 5,3 \\
\hline
\end{tabular}

$70,0 \%$ patients returned to work within 8-15 days in the Desarda group with a mean of 13,4 days while $54,2 \%$ of 14.5 days in the Lichtenstein group, that is significant because in the Lichtenstein group the morbidity is higher patients returned to work within 8-15 days with a mean than in the Desarda group. $(\mathrm{p}<0.05)$ (Table 6). 
A Randomized Trial. Comparing Herniorrafia Modifield Desarda Repair and Hernioplastia Lichtenstein Repair for Inguinal Hernia (Study of 1242 Patients)

Table 6. Return to Work

\begin{tabular}{|c|c|c|c|c|}
\hline \multirow[t]{2}{*}{ PATIENTS RETURNED TO WORK } & \multicolumn{4}{|c|}{ SURGICAL TECHNIQUE } \\
\hline & \multicolumn{2}{|c|}{ LICHTENSTEIN GROUP $\mathrm{n}=640$} & \multicolumn{2}{|c|}{ MODIFIELD DESARDA GROUPn $=602$} \\
\hline & \multicolumn{2}{|c|}{ No. $\%$} & \multicolumn{2}{|c|}{ No. $\%$} \\
\hline 1-7 Days & 25 & 4,0 & 42 & 7,0 \\
\hline 8-15 Days & 347 & 54,2 & 421 & 70,0 \\
\hline 16-30 days & 268 & 41,8 & 139 & 23,0 \\
\hline
\end{tabular}

Lichtenstein Group: Mean: 1-7 days: 6,8 days, 8-15 days: 14,5 days, 16-30 days: 21,3 days. Desarda Group Mean: 1-7 days: 5,7 days, $8-15$ days: 13,4 days, $16-30$ days: 18,4 days.

There was no case of chronic groin pain lasting for more than 6 months in either of the groups. Follow up was complete in over $97 \%$ at 1 year, $92 \%$ at 2 years, $89 \%$ at 3 years, $83 \%$ at 4 years, $80 \%$ at 5

\section{Discussion}

Mesh repair is now widely used in the developed world and is often referred to as the gold standard despite a relative paucity of clinical trials comparing mesh with suture repair. The cost of surgery [7] and the post-operative morbidity affecting the quality of life are important considerations in the inguinal hernia surgery. There are no clear scientific evidences to prove that the mesh prosthetic repair is superior to the non-prosthetic repair in this respect [8]. There are advantages and disadvantages associated with all types of open inguinal hernia repairs. Existing non-prosthetic repair (Bassini/Shouldice) is blamed causing tissue tension and mesh prosthetic repair is blamed for known complications of a foreign body. Dr. Desarda sutures an undetached strip of the external oblique aponeurosis between the muscle arch and the inguinal ligament to give a strong and physiologically dynamic posterior wall [9]. This results in a tension free repair without the use of any foreign body. Being simple to perform it eliminates disadvantage of technical difficulty seen with Should ice repair.

Different studies have tried to give an answer as to which of the existing operation is best for inguinal hernia repair $[10,11]$. The EU Hernia Trialist collaboration [12] made a systematic revision of the randomized prospective studies and the analysis of the results of these different studies. It showed that the duration of surgery was less in hernioplasty in six studies, longer in three and equal in the remaining six. In our group, there was a significant but slight increase in operating time with the Desarda operation. Postoperative pain after mesh prosthetic repair may be less than after Should ice repair because of reduced years, $80 \%$ at 6 years, $76 \%$ at 7 years, $73 \%$ at 8 years, $72 \%$ at 9 years and $70 \%$ at 10 years with no significant difference between the two operation groups.

tension $[12,13]$. Our results have shown that there are no significant differences between the two groups for pain on the first to fifth day after surgery. We found no significant difference in analgesic requirements between the techniques. Overall morbidity was $4.5 \%$, which is similar to the rates described in other studies (7-12\%) [14]. The morbidity rate was higher after the Lichtenstein repair (34 cases, 6.0\% versus 16, $3.0 \%$ in the Modified Desarda group). There were 5 mesh infections after surgery in the Lichtenstein group. Two cases required partial excision of the mesh and in one case, it was associated with recurrence. Modified Desarda technique has lower morbidity as compared to mesh hernioplasty. We believe that the four cases of recurrences seen in Modified Desarda group were due to failure of proper lateralization of the cord and insufficient narrowing of the internal ring as advised by Desarda.

This was evident at re-exploration in those cases that needed only narrowing of the internal ring with few more stitches. In patients admitted to hospital, postoperative stays and the period required to return to normal work after surgery was also significantly in favour of the Modified Desarda group. 45 patients from Lichtenstein group required more than 3 days in the hospital due to local wound complicationsor for some other reasons compared to only 5 patients from the Modified Desarda group, a significant difference. We noted a marked difference in the type of anaesthetic used, $39 \% \mathrm{v} 72 \%$ for local, $54 \% \mathrm{v}$ $25 \%$ for spinal and $7 \%$ v $2 \%$ for general anaesthetic in Lichtenstein Modified Desarda group. This could affect the statistics of hospital stay of the patients who required hospitalization. The external oblique muscle technique satisfies all criteria of modern 
A Randomized Trial. Comparing Herniorrafia Modifield Desarda Repair and Hernioplastia Lichtenstein Repair for Inguinal Hernia (Study of 1242 Patients)

hernia surgery. It is simple and easy to do. It does not require risky or complicated dissection. There is minimal tension in the suture line. It does not require any foreign material and it does not use weak muscle or fascia transversalis for repair. It does not use mesh prosthesis so it is more economical. No foreign body is required in the Desarda repair thus avoiding morbidity associated with foreign bodies including rejection, infection and chronic groin pain.

Jacek Szopinski, et al. [15] stated in their Randomized Controlled Trial (RCT) that the "Desarda technique" has the potential to enlarge the number of tissue based methods available to treat groin hernias. The most evident indications for use of the Modified Desarda technique include use in young patients, in contaminated surgical fields, in the presence of financial constraints, or if a patient disagrees with the use of mesh." Situma, et al. [16] compared Desarda technique with the modified Bassini technique in their RCT and concluded that there is no difference in short-term outcome between Desarda and modified Bassini inguinal hernia repair as regards resumption of normal gait and patterns of pain. Manyilirah [17] concluded in their RCT that the efficacy of the Desarda technique in respect of the early clinical outcomes of hernia repair is similar to that of Lichtenstein method. However the operator in this study showed that the Desarda repair takes a significantly shorter operative time $[18,19]$. The authors therefore conclude that the Modified Desarda repair for inguinal hernia gives the same or better results when compared with the Lichtenstein Mesh repair with shorter hospital stay, more rapid recovery and avoidance of specific mesh related complications whilst also reducing the cost of surgery. It is technically simpler than the Shouldice repair and we recommend that surgeons become acquainted with this technique [20-23].

In a net Shell, the newly proposed Modified Desarda's technique (Combined approach of Desarda's \& Modified Bassini's technique) is amore resilient repair for indirect inguinal herniain terms of late recurrence in contrast to Desarda's procedure alone [24-26].

\section{REFERENCES}

[1] Rutkow MI (1998) Epidemiologic, economic and sociologic aspects of her1. nia surgery in the United States in the 1900s. Surg. North Am 78: 941-951.
[2] Desarda MP (2001) Inguinal herniorrhaphy with an undetached strip 2. of external oblique aponeurosis: a new approach used in 400 patients. Eur J. Surg 167: 01-06.

[3] Porrero JL, Bonachía O, López-Buenadicha A, Sanjuanbenito A, Sán3. chez-Cabezudo C (2005) Reparación de la hernia inguinal primaria: Lichtenstein frente a Shouldice. Estudio prospectivo y aleatorizado sobre el dolor y los costos hospitalarios. Cir Esp 77: 5-8.

[4] Aragon FJ (2001) Nuevas técnicas protésicas para el tratamiento de 4. la hernia inguinal. Ediciones Avila 2001: 22-23.

[5] Price DD, Bush FM, Long S. Harkins SW (1994) A comparison of pain 5. measurement characteristics of mechanical visual analogue and simple numerical rating scales. Pain 56: 217226.

[6] PorreroJL, Sanchez-Cabezudo C, Lee P (1998) Study of unilateral 6. post-herniorrhaphy analgesia with local anaesthetic and monitored anaesthesia care. Ambulatory Surg 6: 211-214.

[7] Costos hospitalarios (2005) Comunicación personal. Departamentoeconómico. Hospital Enrique Cabrera. Enero 2015.

[8] Porrero JL (1999) El cambio de la cirugía de la hernia en la última 8. década. En: Celdran A., de la Pinta JC, editores. Fundamentos de la hernioplastia sin tensión. Madrid: Fundación Jiménez Díaz 1999: 9-11.

[9] MP Desarda (2003) Surgical physiology of inguinal hernia repair-a 9. study of 200 cases. BMC Surgery 3: 1-9.

[10] Simons MP, Kifignen J, Van Geldere D, Hoitsma HFW, Obertop H 10. (1996) Role of the Shouldice technique in inguinal hernia repair: a systematic review of controlled trials and meta-analysis. $\mathrm{Br}$ J Surg 83:734-738.

[11] McGillicuddy JE (1998) Prospective randomized comparison of the 11. Shouldice and Lichtenstein hernia repair procedures. Arch Surg133: 974978.

[12] EU Hernia Trialist Collaboration (2000) Mesh compared with non-mesh 12 . methods of open groin hernia repair: systematic review of randomized controlled trials. Br J Surg 87: 854859. 
A Randomized Trial. Comparing Herniorrafia Modifield Desarda Repair and Hernioplastia Lichtenstein Repair for Inguinal Hernia (Study of 1242 Patients)

[13] Kingsnorth AN, Porter Chs, Bennett DH, Walker AJ, Hyland ME, et al. 13. (2000) Lichtenstein patch or prefix plug and patch in inguinal hernia: a prospective double-blind randomized controlled trial of short-term outcome. Surgery 127: 276-283.

[14] Gilbert AI and Felton IL (1993) Infection on inguinal hernia repair con14. sidering biomaterials and antibiotics. SurgGynecol 117: 126-130

[15] Jacek Szopinski, Stanislaw Dabrowiecki, Stanislaw Pierscinski, Marek15. Jackowski, Maciej Jaworski, et al. (2012) Desarda Versus Lichtenstein Technique for Primary Inguinal Hernia Treatment: 3-Year Results ofa Randomized Clinical Trial. World J Surg 36: 984-992.

[16] S M Situma, S. Kaggwa, N.M. Masiira, S.K. Mutumba (2009) Com16. parison of Desarda versus Modified Bassini inguinal Hernia Repair: A Randomized controlled trial. East Cent. Afr. j. surg14:70-76.

[17] Manyilirah W, Kijjambu S, Upoki A, Kiryabwire J (2012) Comparison 17. of non-mesh (Desarda) and mesh (Lichtenstein) methods for inguinal hernia repair among black African patients: a short-term double-blind RCT. Hernia 16: 133144.

[18] Yousset T, El-Alfy K, Farid M (2015) Randomized Clinical trial of pri18. mary inguinal hernia. Int J Surg 20: 28-34

[19] Dieng M, Cisse M, Seek M, Diallo FK, Tourè AD, et al. (2012) Cure 19. des hernies inguinales simples de L' adulte pastie avec L' aponèurose du grand oblique: Technique de Desarda. e-mèmoires de L'Acadèmie Nationale de Chirurgie 11: 069-074.

[20] Jianxin Z, Dong JW, Zhiyong Z (2013) Desarda inguinal hernia repair 20 . and synthetic patch (open VS TEP) hernia repair comparative study. J Chinese Her and abdominal Surg 7: 559-563

[21] Lòpez Roduìguez PR, Pol Herrera PG, Lèon Gonzàlez OC, Cruz Alon21. so JR, Rodrìguez Blanco HS (2013) A Randomized Trial Comparing Lichtenstein repair and no mesh Desarda repair for inguinal Hernia: A Study of 1382 patients. East Cent Afr J Surg 2013.

[22] Stephen JN and Bruce T (2013) Abdominal wall, herniaandhernia and umbilicus, 22. Bailey and Love's; Short practice of surgery; 26th edn 2013: 957-958.

[23] Szopinski J, Dabrowiecki S, Pierscinski S, Jackowski M, Jaworski M, 23. etal. (2012) Desarda Versus Lichtenstein Technique for Primary Inguinal HerniaTreatment: 3-Year Results of a RandomizedClinical Trial; World J Surg 36: 984992.

[24] Faruquzzaman, Kumar Mazumder S, Mozammel Hossain S (2016) 24. Dinaipur Med Col J 2016 9: 194-201.

[25] Lòpez Rodrìguez PR, Danta Fundora LM, Leòn Gonzàlez OC, Satorre Rocha JA, Garcia Castillo E, Durades Casanova A, Pol Herrera P. A Randomized Trial Comparing Modified Desarda Repair No Mesh and Lichtenstein Repair for Inguinal Hernia ( A study of 1113 Patients ). Journal of Surgery2018; Vol 2018(07): J surgery an open access journal.

[26] Lopez Rodrìguez PR, Leòn Gonzàlez OC, Satorre Rocha Pol Herrera P, Garcia Castillo E, Durades Casanova A, Danta Fundora LM. A Randomized trial Comparing Desarda repair no Mesh and Lichtenstein repair for inguinal hernia (A study of 2225 patients).Biomedical journal of Scientific \& Technical Research. 2018; Vol 6(4) https:// biomedica.us/submit-manuscript.php.

Citation: Dr. Pedro Rolando Lòpez Rodrìguez, Dr. Eduardo Garcia Castillo, et al. A Randomized Trial. Comparing Herniorrafia Modifield Desarda Repair and Hernioplastia Lichtenstein Repair for Inguinal Hernia (Study of 1242 Patients). Open Journal of Geriatrics. 2019; 2(2): 24-30.

Copyright: (C) 2018 Dr. Pedro Rolando Lòpez Rodrìguez, Dr. Eduardo Garcia Castillo, et al. This is an open access article distributed under the Creative Commons Attribution License, which permits unrestricted use, distribution, and reproduction in any medium, provided the original work is properly cited. 